\title{
Genetic relationships among Eurasian Puccinellia distans genotypes
}

\author{
Cantuğ Bar, Sami Doğanlar, Anne Frary* \\ Department of Molecular Biology and Genetics, Science Faculty, Izmir Institute of Technology, Izmir, 35430, Turkey
}

\section{A R T I C L E I N F O}

\section{Article history:}

Received 13 April 2015

Received in revised form 22 July 2015

Accepted 26 July 2015

Available online 3 August 2015

\section{Keywords:}

Sequence related amplified polymorphism markers

SRAP

Weeping alkali grass

\begin{abstract}
A B S T R A C T
Puccinellia distans (Jacq.) Parl. is a common grass species found throughout the world. It can grow in arid and saline environments as well as under toxic boron concentrations. In this work we performed sequence related amplified polymorphism (SRAP) marker analysis on 20 wild $P$. distans genotypes to understand the genetic relationships among different genotypes and subspecies. We tested 119 SRAP primer pairs and found that 43 were polymorphic. The molecular data were then analyzed to determine the genetic relationships and population structure of the genotypes. We were able to trace the origin of genotypes that were carried to distant locations or gathered for research purposes. We also found that geographical distance between genotypes was not an important determinant of genetic relationships as even distantly located Puccinellia genotypes were closely related. As $P$. distans is known to be tolerant to salinity stress and toxic mineral concentrations, the findings of this work can be used as a starting point for selection of genotypes that should be tested under such conditions.
\end{abstract}

() 2015 Elsevier Ltd. All rights reserved.

\section{Introduction}

Puccinellia distans (Jacq.) Parl., more commonly known as weeping alkali grass, is a perennial grass species originating from Eurasia (Hitchcock, 1971; Tarasoff et al., 2007). P. distans has been dispersed throughout the world via different methods including wind, traffic flow (Scott and Davison, 1985; Šera, 2010) and potentially even in mud stuck to cars (Schmidt, 1989). Currently, $P$. distans and its subspecies are most frequently found in saline meadows, alkaline waterside sand and gravel, along roads, in oases, and near springs (Grubov, 2001). In previous studies, weeping alkali grass was shown to have good tolerance to salt, drought and other abiotic stress conditions (Hughes et al., 1975). In addition, it is a hyperaccumulator of boron and can grow in areas with boron levels that are toxic to other species (Stiles et al., 2010). For this reason, P. distans is a good model for phytoremediation of soil in boron polluted areas and has been investigated for such use in previous studies (Aydın and Çakır, 2009; Stiles et al., 2011).

The study of genetic diversity is important because it helps in understanding the amount of variability present in individuals and populations. Such variability can tell us about an organism's past and help to determine its vulnerability to future environmental conditions. Molecular markers are often used to study diversity and to determine genetic relationships among accessions/genotypes within a species in different locations. Sequence related amplified polymorphism markers (SRAPs) are simple and reliable molecular markers that can be used for DNA fingerprinting with a moderate throughput ratio

\footnotetext{
* Corresponding author.

E-mail address: annefrary@iyte.edu.tr (A. Frary).
} 
(Li and Quiros, 2001). SRAP markers are especially suited to studies of genetic diversity because they target random coding sequences within the genome. Such sequences tend to mutate less frequently than non-coding regions and provide a moderate number of markers (Li and Quiros, 2001). These properties of SRAP markers are important since the genotypes used in this work are not inbred. They are wild genotypes which may have several different alleles that can be used to determine their genetic relationships.

In this work we used SRAP markers to analyze the genetic relationships between $P$. distans genotypes collected from different countries as well as different locations within the same country. Although the phylogenetic relationships among Puccinellia species and other grasses were examined by Choo et al. (1994), this is the first systematic work using genotypes of $P$. distans from different locations of the world. We performed our work with 20 genotypes of $P$. distans, 17 of which were collected from nature in mid-Eurasia and three used for research purposes in the USA.

\section{Materials and methods}

\subsection{Plant material}

A total of 20 P. distans genotypes from different locations were used in this work (Table 1). Nineteen of these varieties were provided by the Germplasm Resource and Information Network, United States Department of Agriculture (GRIN, USDA), Washington DC and one was provided by Mehmet Babaoglu, Department of Field Crops, Faculty of Agriculture, Selcuk University, Konya Turkey. Plants were germinated in potting soil and grown for two weeks until they were approximately $10 \mathrm{~cm}$ long. Fresh leaves were immediately used for DNA extraction.

\subsection{DNA extraction}

DNA was extracted as bulk from leaves of approximately 20 plants of the each accession following a modified CTAB extraction method (Doyle and Doyle, 1990). After extraction, DNA concentration was determined by spectrophotometric measurement. Concentration of the samples was adjusted to $20 \mathrm{ng} / \mu \mathrm{l}$. All genetic materials were stored at $-20{ }^{\circ} \mathrm{C}$.

\subsection{Molecular marker analysis}

SRAP analysis was performed with 7 forward and 17 reverse primers. A total of 119 forward and reverse primer combinations were tested using ME1 to ME7 and EM1 to EM17, respectively (Table 2). PCR mix consisted of $2 \mu 1$ of $10 \mathrm{X}$ PCR Buffer, $0.01 \mathrm{mM} F$ and R primers, $25 \mathrm{mM} \mathrm{MgCl}_{2}, 20 \mathrm{ng} / \mu \mathrm{l}$ Genomic DNA, $0.75 \mu \mathrm{l}$ of $40 \mathrm{mM}$ dNTP mix, $1 \mathrm{U}$ Taq polymerase; $8.25 \mu \mathrm{l} \mathrm{H} \mathrm{O}$ to a total of $20 \mu \mathrm{l}$. PCR amplification was performed in two stages. The first stage started with 5 min at $94{ }^{\circ} \mathrm{C}, 1 \mathrm{~min}$ at $94{ }^{\circ} \mathrm{C}$, $1 \mathrm{~min}$ at $35^{\circ} \mathrm{C}, 1 \mathrm{~min}$ at $72^{\circ} \mathrm{C}$ for 5 cycles. The second stage continued with $1 \mathrm{~min}$ at $94{ }^{\circ} \mathrm{C}, 1 \mathrm{~min}$ at $50{ }^{\circ} \mathrm{C}, 1 \mathrm{~min}$ at $72{ }^{\circ} \mathrm{C}$, for 35 cycles finishing with $10 \mathrm{~min}$ at $72{ }^{\circ} \mathrm{C}$. PCR products were then separated on $1 \%$ agarose gels and bands were observed in BioRad Gel Doc XR imaging system.

Table 1

Puccinellia distans genotypes from different locations in mid-Eurasia used in this study.

\begin{tabular}{|c|c|c|c|c|}
\hline No & Accession & Species name & Origin & Source \\
\hline 1 & Eskişehir & Puccinellia distans (Jacq.) Parl. ssp. distans & Turkey & Selcuk University \\
\hline 2 & PI311722 & P. distans ssp. borealis & Turkey & GRIN \\
\hline 3 & PI316340 & P. distans ssp. borealis & Turkey & GRIN \\
\hline 4 & PI384942 & P. distans & Iran & GRIN \\
\hline 5 & PI381010 & P. distans & Iran & GRIN \\
\hline 6 & PI381009 & P. distans & Iran & GRIN \\
\hline 7 & PI381008 & P. distans & Iran & GRIN \\
\hline 8 & PI229458 & P. distans ssp. sevangensis & Iran & GRIN \\
\hline 9 & PI230249 & P. distans & Iran & GRIN \\
\hline 10 & PI230250 & P. distans & Iran & GRIN \\
\hline 11 & PI221955 & P. distans & Afghanistan & GRIN \\
\hline 12 & PI251220 & P. distans & Afghanistan & GRIN \\
\hline 13 & PI578856 & P. distans FULTS strain & USA & GRIN \\
\hline 14 & PI600922 & P. distans FULTS strain & USA & GRIN \\
\hline 15 & PI443386 & P. distans & USA & GRIN \\
\hline 16 & PI502581 & P. distans & Former Soviet Union & GRIN \\
\hline 17 & PI502580 & P. distans & Russian Federation & GRIN \\
\hline 18 & PI502582 & P. distans & Russian Federation & GRIN \\
\hline 19 & PI440628 & P. distans & Kazakhstan & GRIN \\
\hline 20 & PI251164 & P. distans ssp. limosa & Former Serbia and Montenegro & GRIN \\
\hline
\end{tabular}


Table 2

Forward and reverse primers used in SRAP analysis.

\begin{tabular}{|c|c|}
\hline Primer & Sequence \\
\hline ME1 (Forward) & 5'TGAGTCCAAACCGGATA3' $^{\prime \prime}$ \\
\hline ME2 (Forward) & 5'TGAGTCCAAACCGGAGC3' \\
\hline ME3 (Forward) & 5'TGAGTCCAAACCGGAAT3' \\
\hline ME4 (Forward) & 5'TGAGTCCAAACCGGACC $3^{\prime}$ \\
\hline ME5 (Forward) & 5'TGAGTCCAAACCGGAAG3' \\
\hline ME6 (Forward) & 5'TGAGTCCAAACCGGTAG3' \\
\hline ME7 (Forward) & 5'TGAGTCCAAACCGGTTG3' \\
\hline EM1 (Reverse) & 5'GACTGCGTACGAATTAAT3' \\
\hline EM2 (Reverse) & 5'GACTGCGTACGAATTTGC3' \\
\hline EM3 (Reverse) & 5'GACTGCGTACGAATTGAC3' \\
\hline EM4 (Reverse) & 5'GACTGCGTACGAATTTGA3' \\
\hline EM5 (Reverse) & 5'GACTGCGTACGAATTAAC ${ }^{\prime}$ \\
\hline EM6 (Reverse) & 5'GACTGCGTACGAATTGCA3' \\
\hline EM7 (Reverse) & 5'GACTGCGTACGAATTATG3' \\
\hline EM8 (Reverse) & 5'GACTGCGTACGAATTAGC3' \\
\hline EM9 (Reverse) & 5'GACTGCGTACGAATTACG3' \\
\hline EM10 (Reverse) & 5'GACTGCGTACGAATTTAG3' \\
\hline EM11 (Reverse) & 5'GACTGCGTACGAATTTCG 3' \\
\hline EM12 (Reverse) & 5'GACTGCGTACGAATTGTC ${ }^{\prime}$ \\
\hline EM13 (Reverse) & 5'GACTGCGTACGAATTGGT3' \\
\hline EM14 (Reverse) & 5'GACTGCGTACGAATTCAG3' \\
\hline EM15 (Reverse) & 5'GACTGCGTACGAATTCGT3' \\
\hline EM16 (Reverse) & 5'GACTGCGTACGAATTCGG3' \\
\hline EM17 (Reverse) & $5^{\prime}$ GACTGCGTACGAATTCCA3 ${ }^{\prime}$ \\
\hline
\end{tabular}

\subsection{Data analysis}

Agarose gel electrophoresis results were interpreted and polymorphic bands were determined for each primer pair. A scoring matrix was constructed with a score of 1 used for the presence of a specific band and 0 for the absence of that band. The matrix was processed in the DARwin5 (Perrier and Jacquemoud-Collet, 2006) program into a dissimilarity matrix using the Jaccard algorithm. The dissimilarity matrix was then used to reconstruct a tree with the unweighted neighbor joining method and the fit of the matrix to the tree was calculated with the fit criterion built in the program. Data were also subjected to a second analysis program, Structure (Pritchard et al., 2000). This program was used to calculate subpopulation (K) structure using $\mathrm{K}$ values of $1-10$ with 20 iterations.

\section{Results}

In this work, seven forward primers (ME1 to ME7) and 17 reverse primers (EM1 to EM 17) were assayed on 20 P. distans genotypes. Of these 119 primer pair combinations, 43 (36.1\%) were polymorphic. The polymorphic primer pairs provided 219 polymorphic bands which were scored for further analysis.

The dissimilarity matrix computed from the marker data gave a minimum value of 0.07 between genotypes PI502581 (16) and PI443386 (15) indicating that these genotypes were highly similar. The maximum dissimilarity between genotypes was 0.84 and was calculated between PI230249 (9) and Eskişehir (1) meaning that these genotypes are very different from each other. The dissimilarity analysis gave an overall average score of 0.65 .

Using the dissimilarity matrix, an unweighted neighbor-joining tree was drawn (Fig. 1) with a very strong correlation between the distance matrix and the neighbor-joining dendrogram $(r=0.99)$. The genotypes fell into two main clusters. Cluster 1 had 11 genotypes and three subclusters: A, B and C. Cluster 1 mainly consisted of genotypes located in the eastern part of mid-Eurasia. This cluster had an average dissimilarity index of 0.65 with minimum and maximum values of 0.07 and 0.82 , respectively. Cluster 2 had seven genotypes that were mainly collected in the western part of mid-Eurasia except for PI440628 (19) which was from Kazakhstan. In this cluster, the average dissimilarity index was 0.53 with minimum and maximum values of 0.31 and 0.66 , respectively. Lastly cluster 3, containing genotypes PI316340 (3) and PI311722 (2) was an outgroup of the other two clusters as expected because these two genotypes are a subspecies of $P$. distans Parl. ssp. borealis (Holmberg) W.E. Hughes. The analysis performed with Structure data program supported the defined clusters however, five genotypes: PI384942 (4), PI230249 (9), PI578856 (13), PI600922 (14), and PI440628 (19) were found to be admixed (data not shown).

\section{Discussion}

Although P. distans, does not have any economic value, it possesses unique properties for abiotic stress tolerance and hyperaccumulation of toxic boron (Hughes et al., 1975; Stiles et al., 2010). The accessions we studied were collected from 


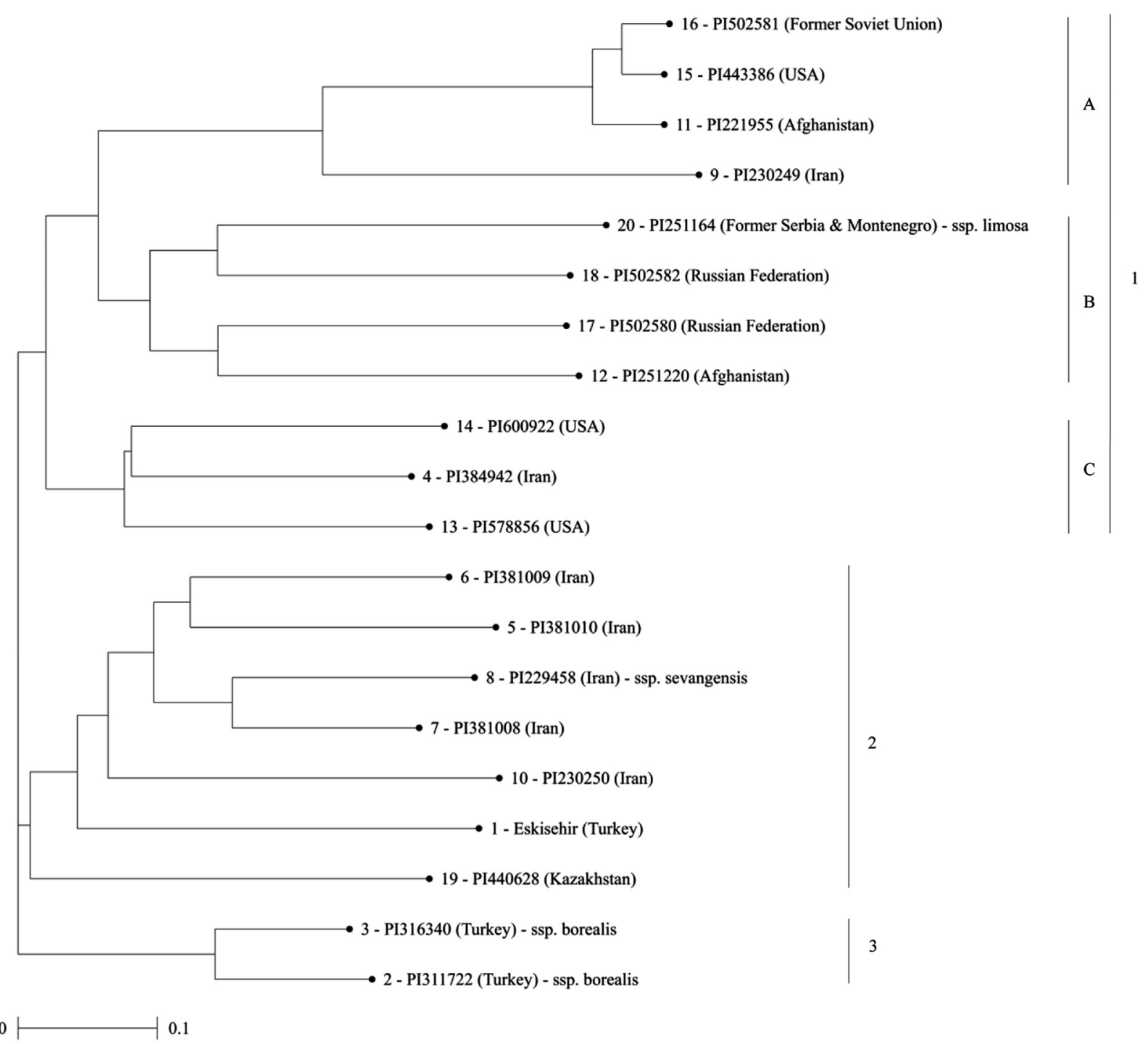

Fig. 1. Unweighted neighbor joining tree of $P$. distans genotypes. The tree contains three clusters: 1,2 and 3 . Cluster 1 contains 3 subclusters A, B and C. Cluster 3 is an outgroup.

various locations and environments and can be used to shed light on the relationship between the genotypes and their abiotic stress resistance phenotypes. Previously, Choo et al. (1994) performed work with 20 different Puccinellia accessions, three of which were used in this work, and constructed a phylogenetic tree. They obtained PI251164 (20), PI311722 (2) and PI384942 (4) from the Plant Introduction Station not as subspecies of $P$. distans, but as different species: $P$. limosa (20) and $P$. poecilantha (2 and 4). However, PI251164 (20) was received as P. distans (Jacq.) Parl. ssp. limosa (Schur) Soó and Jáv, from GRIN in this work and clustered with other P. distans accessions (Fig. 1) while PI311722 (2) was identified as subspecies borealis and PI384942 (4) simply as P. distans. In agreement with their re-classification by GRIN, PI311722 and PI251164 were found in different clusters. PI311722 (2) clustered as outgroup with another ssp. borealis accession, PI316340 (3) while PI384942 (4) was placed in subcluster $\mathrm{C}$ with other $P$. distans accessions. This organization shows a more distant relationship between these two accessions than that shown by Choo et al. (1994).

Because P. distans is not native to the Americas, it is assumed that PI578856 (13), PI600922 (14) in and PI443386 (15) were donated to the USA from other countries for research purposes and their original location is unknown. Genotypes PI578856 (13), PI600922 (14) were renamed FULTS and described in a turfgrass seed guide (Sports Turf Research Institute, 1981). According to our results, the origin of these registered landraces may be Iran because they are closely related to accession PI384942 (4). Interestingly, the two FULTS genotypes were only 54\% similar indicating that they were selected from genetically distinct material. The other US genotype, PI443386 (15) probably originated from Russia as it was only slightly (0.06) dissimilar from PI502581. 
Genotypes from Iran clustered with other Middle Eastern genotypes from Turkey and Kazakhstan. Because genotype PI229458 (8) is known to be P. distans Parl. ssp. sevangensis (Grossh.) Tzvelev, it is possible that the closely related genotypes from Iran, especially PI381008, may also be ssp sevangensis. Also located in this cluster is a genotype from Eskisehir, Turkey. This genotype is a boron hyperaccumulator and is able to accumulate $3.30 \mathrm{mg}$ of boron per g of dry leaf tissue when grown in modified half strength Hoagland solution with $500 \mathrm{mg} \mathrm{B/L}$ (Stiles et al., 2010). Thus, it is possible that other genotypes in cluster 2 may be able to hyperaccumulate boron. Genotypes PI381008 (7) and PI381010 (5) are especially interesting and should be tested for such properties because they were collected near a salt flat and an alkali spot, respectively.

The outgroup cluster consisted of two genotypes of $P$. distans ssp. borealis from Kakliç Turkey. These two genotypes, accessions PI316340 (3) and PI311722 (2), showed low dissimilarity, a value of 0.20, indicating that they are closely related. This was expected as they were collected from the same location. The other two subspecies of $P$. distans, ssp. limosa and ssp. sevangensis, did not fall into the outgroup but, instead were clustered with P. distans genotypes. PI251164 (20) ssp. limosa was found in cluster 1, as already indicated, and PI229458 (8) ssp. sevangensis was found in cluster 2. Thus, our results, only showed a clear genetic distinction between ssp. borealis and the rest of the P. distans material.

While it is often expected that more closely located genotypes will be more closely related, we found that some distantly located genotypes were genetically similar. This seeming discrepancy may be explained by the anemochorous mode of seed dispersal of $P$. distans as well as the dispersal of seeds by motor vehicles between long distances as explained by Schmidt (1989). To further support this hypothesis, more samples from countries in the region should be gathered and added to the analysis. If enough genotypes are added, we may be able to see the pattern of dispersal and possibly find the point of origin of $P$. distans species. In establishing genetic relationships between $P$. distans accessions, this work may shed light on their physiological properties since certain genotypes of $P$. distans are known to be tolerant to drought, salt and boron abiotic stress (Hughes et al., 1975; Stiles et al., 2010). Thus, this work may be used as a starting point for selection of $P$. distans genotypes that should be tested for toxic mineral hyperaccumulation and abiotic stress tolerance.

\section{Acknowledgments}

This research was supported by the Scientific and Technological Research Council of Turkey (113Z930). We also would like to thank Mehmet Babaoğlu for providing the P. distans seeds from Eskişehir, Turkey.

\section{References}

Aydın, M., Cakır, F., 2009. Research on weed species for phytoremediation of boron polluted soil. Afr. J. Biotechnol. 8.

Choo, M.K., Soreng, R.J., Davis, J.I., 1994. Phylogenetic relationships among Puccinellia and allied genera of Poaceae as inferred from chloroplast DNA restriction site variation. Am. J. Bot. 119-126.

Doyle, J.J., 1990. Isolation of plant DNA from fresh tissue. Focus 12, 13-15.

Grubov, V.I., 2001. Key to the Vascular Plants of Mongolia (With an Atlas), vol. I and II. Science Publishers, Inc.

Hitchcock, A.S., 1971. Manual of the Grasses of the United States. Courier Corporation.

Hughes, T., Butler, J., Sanks, G., 1975. Salt tolerance and suitability of various grasses for saline roadsides. J. Environ. Qual. 4, 65-68.

Li, G., Quiros, C.F., 2001. Sequence-related amplified polymorphism (SRAP), a new marker system based on a simple PCR reaction: its application to mapping and gene tagging in Brassica. Theor. Appl. Genet. 103, 455-461.

Perrier, X., Jacquemoud-Collet, J., 2006. DARwin Software.

Pritchard, J.K., Stephens, M., Rosenberg, N.A., Donnelly, P., 2000. Association mapping in structured populations. Am. J. Hum. Genet 67 (1), 170-181.

Schmidt, W., 1989. Plant dispersal by motor cars. Vegetatio 80, 147-152.

Scott, N., Davison, A., 1985. The distribution and ecology of coastal species on roadsides. Vegetatio 62, 433-440.

Šera, B., 2010. Road-side herbaceous vegetation: life history groups and habitat preferences. Pol. J. Ecol 58, 69-79.

Stiles, A.R., Bautista, D., Atalay, E., Babaoğlu, M., Terry, N., 2010. Mechanisms of boron tolerance and accumulation in plants: a physiological comparison of the extremely boron-tolerant plant species, Puccinellia distans, with the moderately boron-tolerant Gypsophila arrostil. Environ. Sci. Technol. 44, 7089-7095.

Stiles, A.R., Liu, C., Kayama, Y., Wong, J., Doner, H., Funston, R., Terry, N., 2011. Evaluation of the boron tolerant grass, Puccinellia distans, as an initial vegetative cover for the phytorestoration of a boron-contaminated mining site in southern California. Environ. Sci. Technol. 45 , $8922-8927$.

Tarasoff, C., Mallory-Smith, C., Ball, D., 2007. Comparative plant responses of Puccinellia distans and Puccinellia nuttalliana to sodic versus normal soil types. J. Arid. Environ. 70, 403-417. 